\title{
Analysis and Performance Of Grid Connected Straight Driven Pmsg Based Wind Turbines
}

\author{
Eswaraiah Ga, Dr. A A Ansarib \\ a Research Scholar, Dept. of Electrical and Electronics Engineering, \\ Sri Satya Sai University of Technology \& Medical Sciences, Sehore, Bhopal Indore Road, Madhya Pradesh, India \\ ${ }^{\mathbf{b}}$ Research Guide, Dept. of Electrical and Electronics Engineering, \\ Sri Satya Sai University of Technology \& Medical Sciences, Sehore, Bhopal Indore Road, Madhya Pradesh, India
}

Article History: Received: 11 January 2021; Accepted: 27 February 2021; Published online: 5 April 2021

\begin{abstract}
Permanent-magnet synchronous generator (PMSG) are used widely in wind turbine applications. The performance analysis of PMSG can be enhanced by adopting a number of control mechanisms with the benefit of advanced optimization techniques. Renewable energy is harnessed from continuously replenishing natural processes. Some commonly known are sunlight, water, wind, tides, geothermal heat and various forms of biomass. The focus on renewable energy has over the past few decades intensified greatly. This paper presents modeling and control strategy for the grid connected wind turbine system based on Permanent Magnet Synchronous Generator (PMSG). The considered system is based on back-to-back converter topology. The Grid Side Converter (GSC) achieves the DC bus voltage control and unity power factor. The Machine Side Converter (MSC) assures the PMSG speed control. The PMSG is used as a variable speed generator and connected directly to the turbine without gearbox. The pitch angle control is not either considered in this study. Further, Optimal Tip Speed Ratio based MPPT control strategy is used to ensure the most energy efficiency whatever the wind speed variations. A filter (L) is put between the GSC and the grid to reduce current ripple and to improve the injected power quality.During grid faults, a hierarchical coordinated control scheme for the generator-side converter, main grid-side converter and auxiliary grid-side converter, depending on the grid voltage sags, is presented to enhance the low voltage ride through (LVRT) capability of the direct-driven PMSG WT.
\end{abstract}

Keywords: Permanent-magnet synchronous generator (PMSG), Grid Side Converter (GSC), Machine Side Converter (MSC), Wind turbine, Back-to-back converter.

\section{Introduction}

Renewable energy is the energy that comes from resources which are continually replenished such as sun, wind, rain, tides, waves etc. Among all available choices, the direct driven PMSG based wind turbines are preferred. In a permanent magnet synchronous generator the excitation field is provided with a permanent magnet instead of a coil. Synchronous generators are the majority source of commercial electrical energy. They are commonly used to convert the mechanical power output of steam turbines, gas turbines, reciprocating engines, hydro turbines and wind turbines into electrical power for the grid. They are known as synchronous generators because the speed of the rotor must always match with the supply frequency. In a permanent magnet generator, the magnetic field of the rotor is produced by permanent magnets. Other types of generator use electro magnets to produce a magnetic field in a rotor winding.

The direct current in the rotor field winding is fed through a slip ring assembly or it provided by a brush less exciter. Permanent magnet generators do not require a DC supply for the excitation circuit and it have high efficiency and low maintenance cost, therefore, they have been considered as a promising candidate for new designs in high power applications. In terms of operating mode, variable speed wind turbines possess several advantages over the fixed speed systems such as the ability to obtain maximum power output from varying wind speed, higher efficiency, and lower mechanical stress. In the fault condition of a PMSG based WECS the fault will affect the entire system performance and will lead to an unstable condition. Without control, system will become stable only after a long time, but if sufficient control is provided the stable condition is attained quickly.

\section{Wind Turbine Generator Systems}

The turbines are composed of the rotor of blades that convert the kinetic energy of the wind into mechanical energy, the gearbox that multiplies the speed of the rotor and transmits it to the axis of rotation of the generator, the electric generator, control system and the instrumentation. Figure 2.1 shows a general diagram of wind turbine 


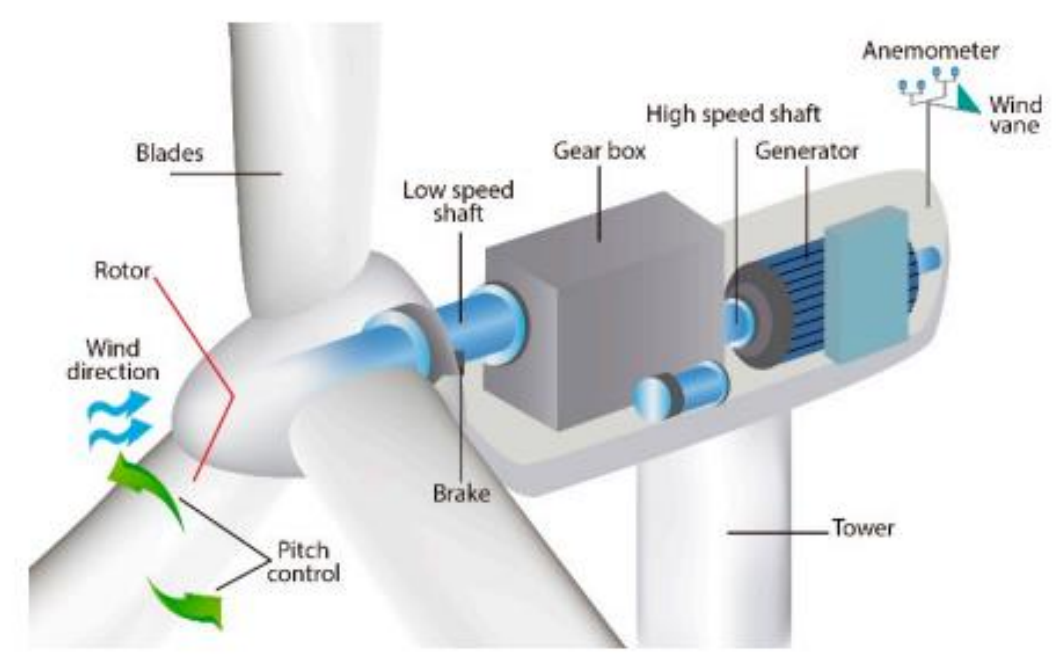

Figure 1. Parts of a wind turbine

To obtain the mathematical model of the wind power extracted by the rotor, an analysis of the wind passing between the blades in the swept area is made. The power extracted by the rotor is described with the following equation:

$$
P_{\text {rotor }}=\frac{1}{2} \rho A V^{3} C p
$$

where the wind density is $\rho$, the sweeping area is $\mathrm{A}$, wind before the turbine is $\mathrm{V}$ and $\mathrm{Cp}$ is a power coefficient. To obtain the value of $\mathrm{Cp}$, an experimental method can be used, dependent of $\lambda$, pitch angle of the blade $\beta$ and $\alpha$ constant. The curve fit is a good approximation for values of $3<\lambda<15$, which are suitable for all blade configurations and models.

$$
\begin{gathered}
C p=\left(\sum_{i=0}^{4} \sum_{j=0}^{4} \alpha_{i, j} \beta^{j} \lambda^{i}\right) \\
\lambda=\frac{w_{r} R}{V}=\frac{2 \pi n R}{60 \mathrm{~V}}
\end{gathered}
$$

where

- $\mathrm{w}_{\mathrm{r}}$ is the rotation frequency $(\mathrm{rad} / \mathrm{s})$,

- $\mathrm{n}$ is the speed of rotation ( $\mathrm{rpm})$

- $\mathrm{R}$ is the radius of the rotor $(\mathrm{m})$.

\section{Terminologies related to Wind Turbine systems}

\section{Angle of attack}

The amount of surface area available for the incoming wind is key to increasing the aerodynamic forces on the rotor blades. The angle at which the blade is adjusted is referred to as the angle of attack. The angle is measured with respect to the relative wind direction and the chord line of the blade.

\section{Pitch Angle}

The angle between the chord and the plane of rotation is called the pitch angle.

3. Cut-in Speed

Cut-in Speed is the minimum wind speed at which the blades will turn and generate usable power.

4. Rated Speed

The rated Speed is the wind speed at which the turbines will generate it's designated rated power. At wind speeds between cut-in and rated, the power output from a turbine increases as the wind speed increases.

\section{Cut-out Speed}

At very high wind speeds, most WT cease power generation and shut down. The wind speed at which shut down occurs is called the cut-out speed.

6. Tip Speed Ratio (TSR)

It is the ratio of the rotating blade tip speed to the speed of the free stream wind. 


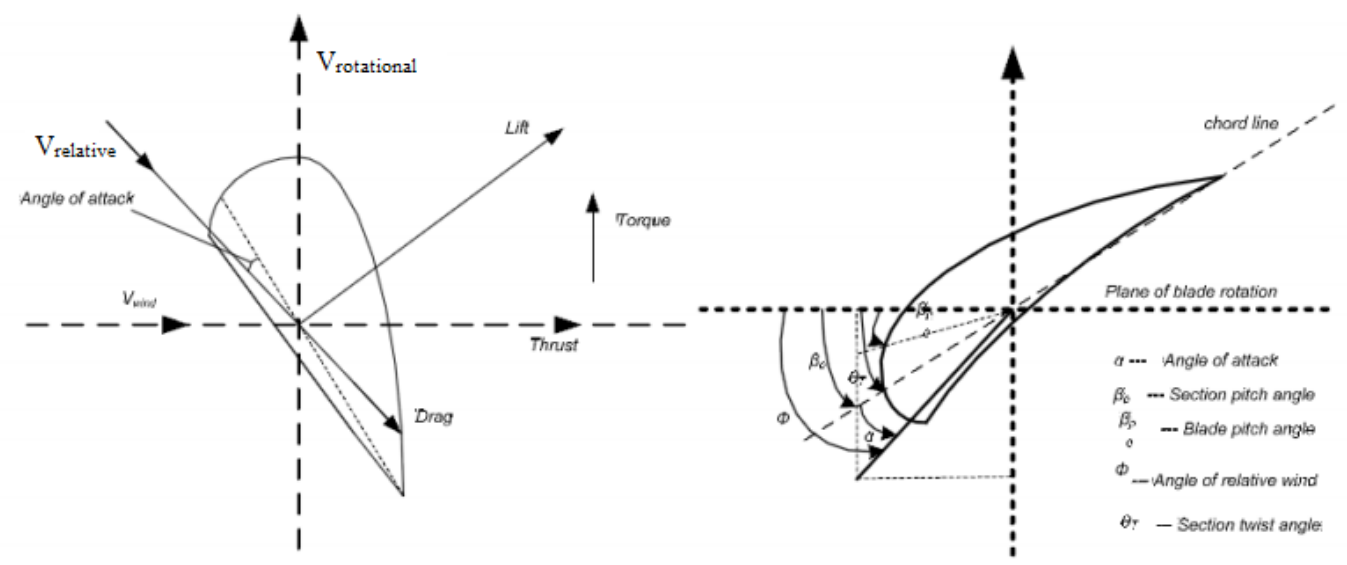

Figure 2: Cross-section of Air foil

Configurations of Wind Energy Conversion System (WECS)

A wind energy conversion system (WECS) converts the kinetic energy of wind speed into electrical energy with the help of wind turbines (wind mills coupled with generators). Wind mill convert the kinetic energy of the wind into mechanical energy. Windmills are coupled to synchronous/asynchronous generators through a drive train. The generators convert the mechanical energy of wind mill to electrical energy (AC form). Electrical energy obtained from the generators is converted into suitable $\mathrm{AC}$ or $\mathrm{DC}$ form depending on the requirement at consumer side. A typical grid-connected or standalone WECS consists of two stages. First stage is the controlled/uncontrolled converter which operates the wind turbine at maximum power points (when using controlled converter) and converts the AC output of the generator into suitable DC form. Second stage is essentially a VSI or CSI which interfaces the wind system to grid or the load. A DC/DC boost converter intermediate stage can also be there. DC/DC boost converter is connected between first and second stage. It is used to boost up the voltage for VSI's DC end voltage.

Based on the blade pitching and speed control of machine WECSs can be broadly listed under the following:

\section{Fixed Speed Fixed Pitch (FSFP)}

It is the configuration where it is impossible to improve performance with active control. In this design the turbine generator is directly coupled to the power grid causing the generator speed to lock to the power line frequency and fix the rotational speed. These turbines are regulated using passive stall methods at high wind speeds. The gearbox ratio selection becomes important for this passive control because this ensures that the rated power is not exceeded.

\section{Fixed Speed Variable Pitch (FSVP)}

This configuration operates at a fixed pitch angle below the rated wind speed and continuously adjusts the angle above the rated wind speed. The fixed speed operation implies a maximum output power at one wind speed only. Both feather and stall pitch control methods can be deployed in this configurations to limit power. But the problems associated with feathering which takes a significant amount of control design while stalling which increases unwanted amount of thrust forces makes this configuration less implementable in real world.

\section{Variable Speed Fixed Pitch (VSFP)}

This configuration continuously adjusts the rotor speed relative to wind speed through power electronics controlling the speed of the generator. In this type of control the generator and the drive train are free to rotate independent of the grid frequency.

\section{Variable Speed Variable Pitch (VSVP)}

This configuration is a derivation of VSFP and FPVS. Operating below the wind speed VSFP are used to maximize the energy capture and increase the power quality. Operating above the rated wind speed, FSVP permit efficient power regulation at the rated power.

\section{Literature Review}

Liang Yuan (2020): The author explain that with the development of renewable energy technology, wind power has become an increasingly significant solution to the worldwide energy crisis. In recent years, much more attention has been attached to wind energy conversion systems. However, due to its inherent uncertainty and intermittency, large-scale utilization of wind power poses great challenges to the secure and reliable energy supply. One is the coordinated reactive power regulation, a problem that has attracted widespread concern with the increasingly high penetration of wind power. Another one is the fault ride-through capability, which is essential to the system resilience during contingencies. As we have witnessed the South Australia blackout in 
2016, cascading trips of wind turbine generators could happen under severe weather conditions and grid voltage disturbance. Among the issues wind energy are facing, the sub synchronous oscillation (SSO) is an emerging but critical one as the unexplained SSO was detected in several permanent magnet synchronous generators (PMSG)based wind farms. Moreover, modern wind farms are usually located in rural areas, and the low short-circuit ratio inevitably results in a weak connection, which has made existing challenges even more complex. This thesis focuses on the PMSG-based wind farms and aims to provide advanced wind farm control for grid integration. The main objectives of this thesis are to (1) propose a hierarchical control scheme for coordinated reactive power regulation to ensure safe wind farm operation; (2) propose a coordinated high voltage ride through and low voltage ride through control scheme to overcome various voltage faults; (3) investigate the emerging PMSG-involved SSO problems through different methods and propose effective damping technique. Furthermore, real-time digital simulation technology is introduced, and a hardware-in-the-loop test platform is constructed to demonstrate the benefits to modern renewable energy integration.

MujaddidMorshed Chowdhury (2019): The author has shared his view that the interest in wind energy system is growing worldwide to reduce dependency on fossil fuel and to minimize the adverse impact of climate change. Currently, doubly fed induction generator (DFIG) based variable speed wind turbine technology with gearbox is dominating the world market share. However, the problems associated with induction generator based wind turbines are reactive power consumption, mechanical stress and poor power quality. Moreover, the gearbox requires regular maintenance as it suffers from faults and malfunctions. The performance of a variable speed wind turbine can be enhanced significantly by using a low speed permanent magnet synchronous generator (PMSG) without a gearbox. The main features of PMSG based wind turbines are; gearless operation, higher efficiency, enhanced reliability, smaller size, reduced cost and low losses. The main aim of this thesis is to develop improved control strategies for an efficient and reliable grid interface system for a gearless, direct drive variable speed wind turbine.

This thesis focuses on several aspects of modelling and control of interior permanent magnet (IPM) synchronous generator based grid connected variable speed wind turbine with maximum power extraction (MPE). Both the indirect and direct control strategies are addressed for IPM synchronous generator based variable speed wind turbines. The main contributions of this thesis are; (i) development of parameter measurement methods to determine the parameter of an IPM synchronous generator, (ii) development of an improved indirect vector control scheme for the IPM synchronous generator based direct drive variable speed wind turbine, incorporating maximum torque per ampere trajectory (MTPA) and maximum power extraction (MPE) algorithm (iii) development of direct torque and flux (DTFC) control scheme for the IPM synchronous generator based direct drive variable speed wind turbine, and (iv) development of control and power management strategy for a three level converter based STATCOM with Supercapacitor energy storage to enhance the performance of the proposed wind energy conversion system under various disturbances.

\section{PROPOSED METHODOLOGY}

As wind energy source is one of the feasible technologies and its application as a DG unit is popular in these days due to economically viable as compared to other clean energy sources. Wind energy power generation could be found from a small number of kilowatts to many more MW in large - scale grid-connected or off-grid small scale standalone systems wind farms. This type of DG causes problem in electrical system due to lack of control on reactive and active power, this type of DG usually causes problems in the electrical power connected system. So, accurate modeling control and most importantly selection of generator is required for WECS. Furthermore, it's so important to research regarding various ways to improve technical control and as well as the performance of plant as there is increase of wind energy power integrated which is being integrated with largescale power system.Recently, variable speed wind turbines (VSWT) have attracted significant interest in electric power generation systems. Two most popular types of VSWTs are wind energy conversion systems with doubly fed induction generators (DFIGs) and permanent magnet synchronous generators (PMSGs). However, WT systems with permanent magnet synchronous generators have instinct advantages over other types of WTs due to low maintenance cost, reliability, and optimum power generation capability.

\section{PMSG WT Configuration with a Parallel Auxiliary GSC}

The typical structure of a direct-driven PMSG WT system is shown in Figure 4.1. The stator winding of the synchronous generator is connected to the grid through a fully rated back-to-back converter. Typically, the generator-side converter controls the active and reactive power output of the PMSG. In contrast, the GSC maintains the DC-link voltage and controls the reactive power exchange between the generator and the grid, i.e., the GSC transfers the active power extracted from the wind turbine to the grid at an adjustable power factor. The DC chopper circuit, which consists of power electronic devices and unloading resistors connected in series, is used to maintain a stable DC-link voltage during power grid faults 


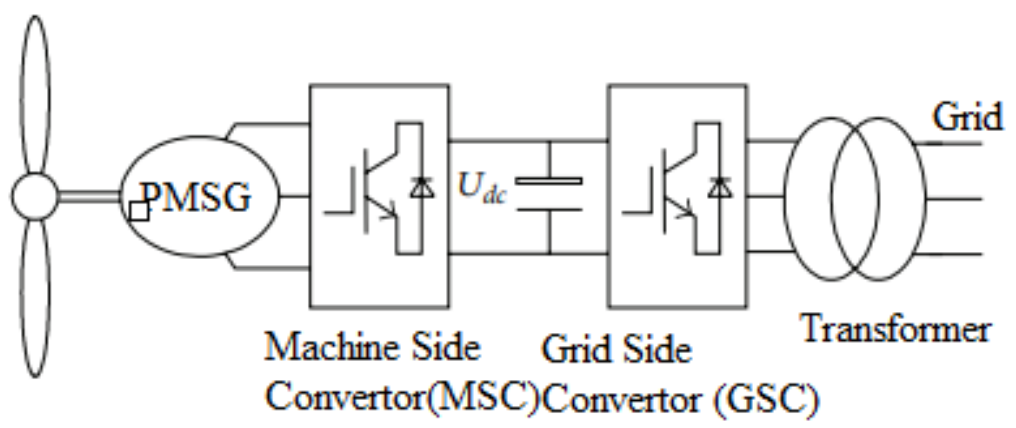

Figure 3: General wind turbine PMSG system with control schemes

The MSC and GSC structures can be in the form of back-to-back VSCs or a combination of diode bridge rectifier- boost converter and VSC. Some research works employ diode bridge rectifier-boost converter as MSC. However, in this paper, the MSC and GSC are indeed in the form of the back-to-back VSCs which are more popular. There are commonly 2 control structures for the grid-connected PMSG based WTs: (1) In the first control structure, MSC is used for the generator output power/speed control, and the GSC for keeping the dc-link voltage constant; (2) In the second control structure, the MSC is used for the control of the dc-link capacitor voltage, and the GSC for the output power control.The second control structure, the sensitivity of the PMSG active power to variations of the wind speed and drive train oscillations is lower than that in the first control mode. Hence, in this paper, the control and stability analysis of the dc-link system is discussed and investigated when the PMSG works with the second control structure.

Figure 4shows the typical structure of a shunt active power filter, which includes a converter, a DC-link capacitor and a filter inductor.

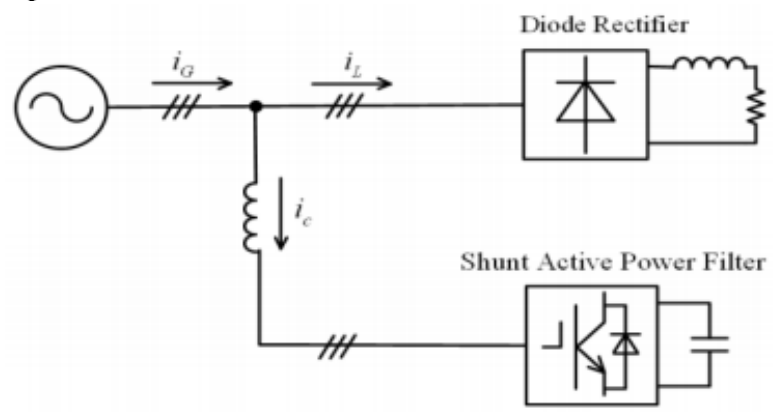

Figure 4. A schematic of a typical parallel Active power Filter.

Many similarities in the control mechanisms of these two systems are readily apparent: for example, a stable DClink voltage is required to control the grid-connected PWSG WTs and to ensure effective compensation by an APF. The DC-link voltage is usually stabilized by regulating the active exchange between the AC side and the DC side of a system. When the DC-link voltage exceeds the reference value, the converter injects active power into the power grid to reduce the DC-link voltage.

These similarities were used to develop a new topology for a direct-driven WT system, which is shown in Figure 5. In the proposed configuration, an auxiliary converter with a half capacity of the GSC, which shares the DClink of the back-to-back converters, is connected in parallel with the GSC in a conventional PMSG WT system.

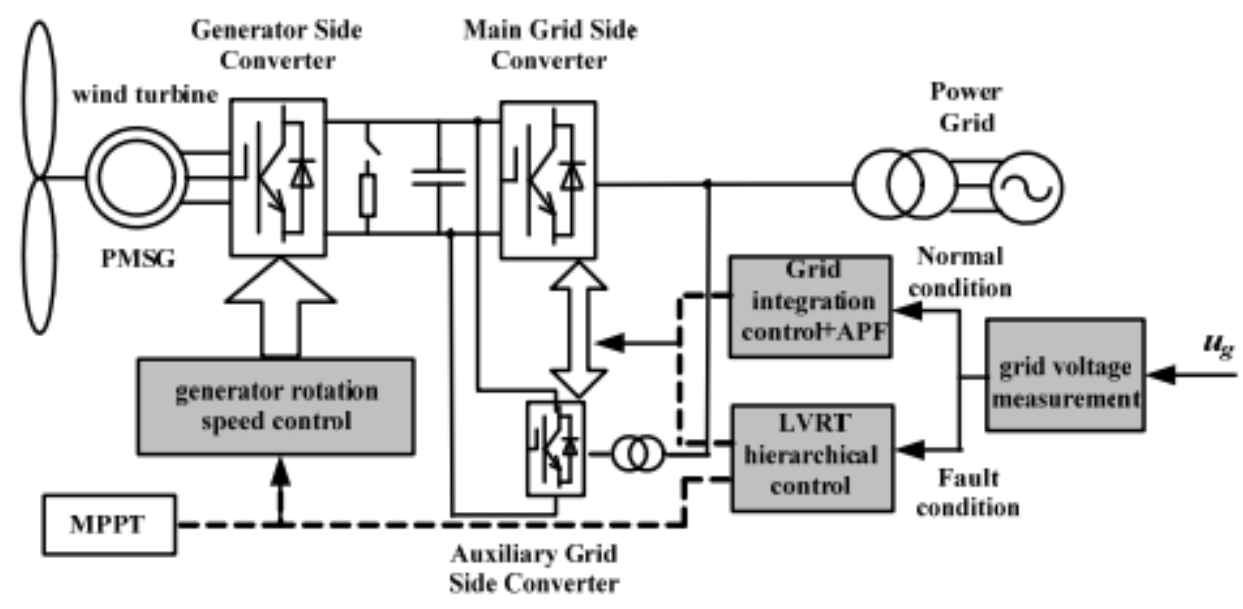




\section{Figure 5. A direct-driven PMSG-based WT system.}

Under normal conditions, the generator-side converter regulates the generator rotation speed by controlling the electromagnetic torque to achieve maximum power point tracking. Meanwhile, the main GSC maintains the DClink voltage to be constant, whereas the auxiliary GSC functions as an APF to implement harmonic current compensation. During the grid voltage dips, by switching the control strategy, the generator-side converter, the GSC and the auxiliary GSC are coordinately controlled to output required active and reactive powers that follow pre-established criteria; this process of hierarchical coordinated control maintains a stable DC-link voltage and provides reactive power support to the power grid to satisfy the LVRT requirements of the grid code.

The main GSC with LC output filter only transfers fundamental power and does not provide harmonics filtering within the control bandwidth, whereas the auxiliary GSC with L output filter compensates harmonics. Hence, according to the parameters of the output filter, the cutoff frequency of the current controllers for the main GSC is designed to be approximate $200 \mathrm{~Hz}$, whereas, to extract up to the 25th harmonics, the cutoff frequency of the current controller for the auxiliary GSC is designed to be $1.28 \mathrm{kHz}$, which is one tenth of the sampling frequency.

\section{Characteristics of straight driven PMSG under short circuit faults}

PMSG is examined under the same conditions of part A. The response of the machine to the fault is shown in Figure6. Once the fault is applied, a transient condition occurs. Fault current increases but does not reach very high values due to the generator series inductance. Generator stator current reaches 4 pu in a second and keeps increasing. If such overcurrent can persist, it may lead to machine's thermal damage. Irreversible demagnetization of magnet material may also be caused. The rotor speed suddenly falls and then keeps oscillating between 0.2 and 3 p.u, which is a heavy burden for the mechanical system. Electromagnetic torque suddenly ramps up to 2 pu and then keeps oscillating, adding high stress on the shaft. Therefore, Unlike SCIG, PMSG has an undesirable response to the fault and hence a protection scheme becomes a must.

Rotor Speed

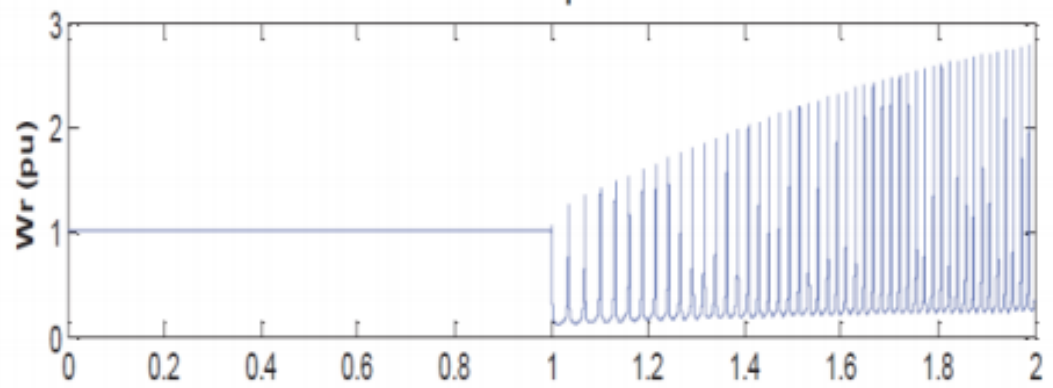

Electromagnetic Generated Torque

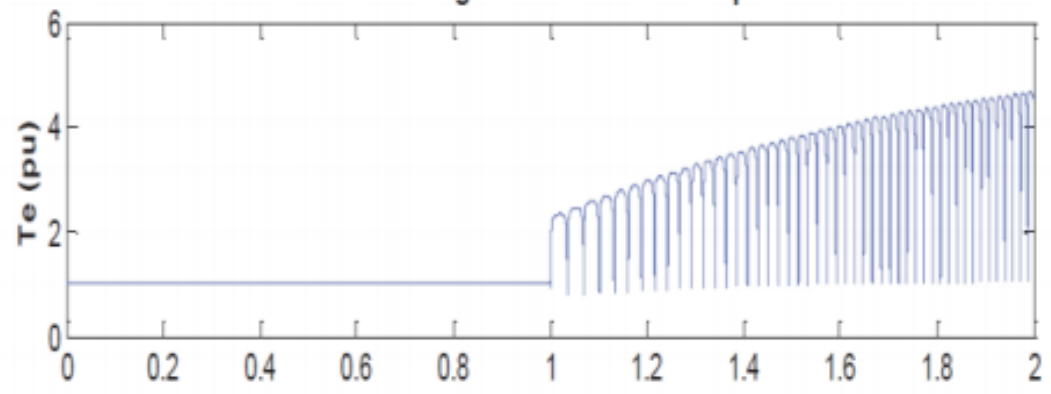



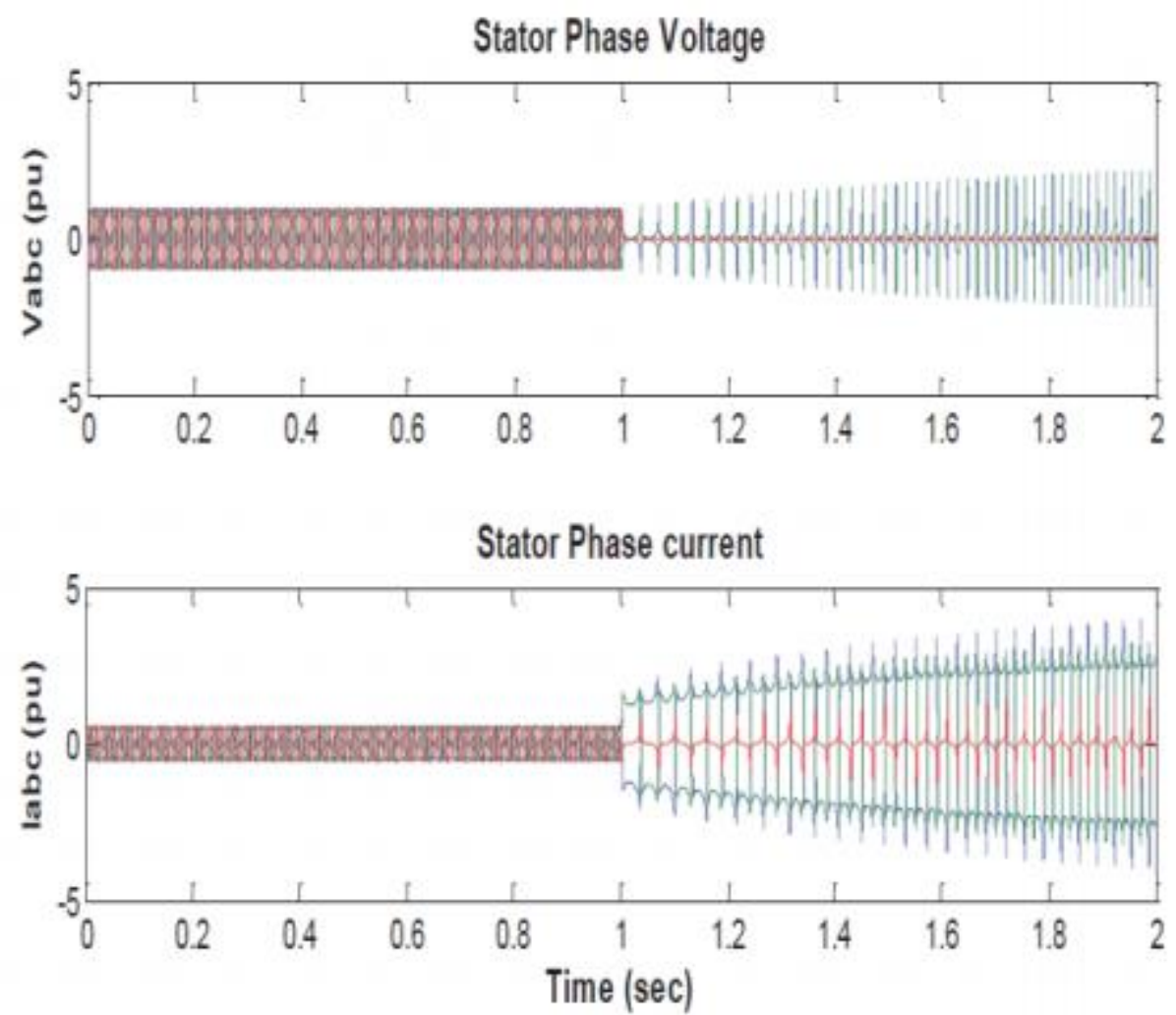

Figure 6. Response of PMSG to short circuit fault Table 1 Active power generated at various wind speeds

\begin{tabular}{|l|l|l|l|}
\hline \multirow{2}{*}{$\begin{array}{c}\text { Wind } \\
\text { Speed } \\
(\mathbf{m} / \mathbf{s})\end{array}$} & \multicolumn{3}{|c|}{ PMSG } \\
\cline { 2 - 4 } & $\mathbf{P g}$ & $\begin{array}{c}\text { Efficiency } \\
(\mathbf{\%})\end{array}$ & $\begin{array}{c}\text { Power } \\
\text { Factor }\end{array}$ \\
\hline 3 & 0.44 & 94.7 & 0.98 \\
\hline 4 & 1.04 & 94.7 & 0.98 \\
\hline 6 & 3.56 & 94.7 & 0.98 \\
\hline 10 & 16.5 & 94.8 & 0.98 \\
\hline 12 & 27.6 & 94 & 0.96 \\
\hline 13 & 33.2 & 94 & 0.96 \\
\hline
\end{tabular}

\section{RESULTS}

The system performance under normal conditions with nonlinear loads. At $t=0.1 \mathrm{~s}$, the auxiliary GSC initiated the APF control mode to implement harmonic compensation for the nonlinear loads around the wind farm. 


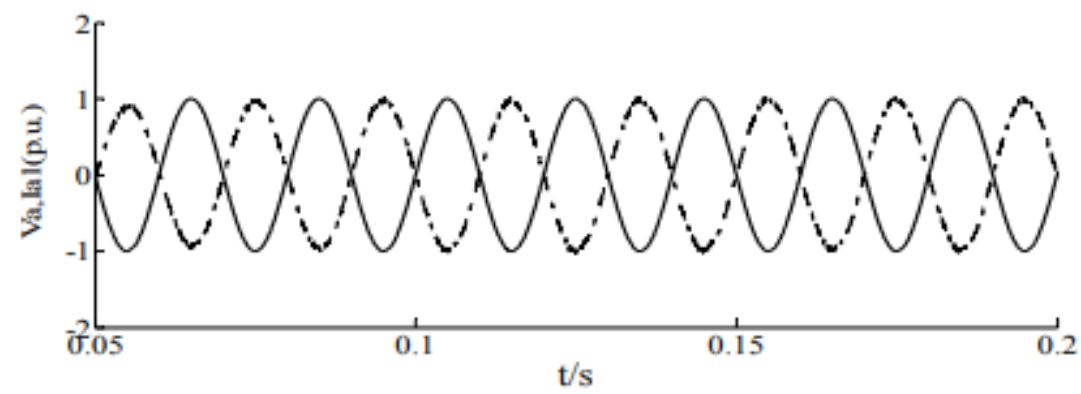

(a)

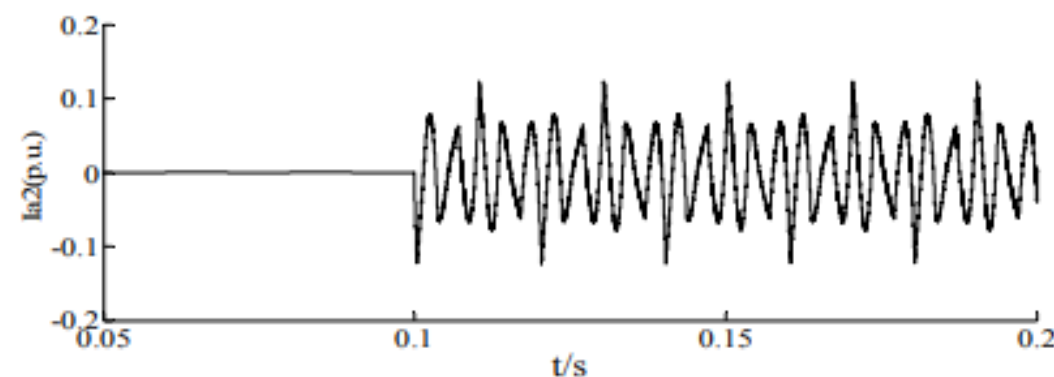

(b)

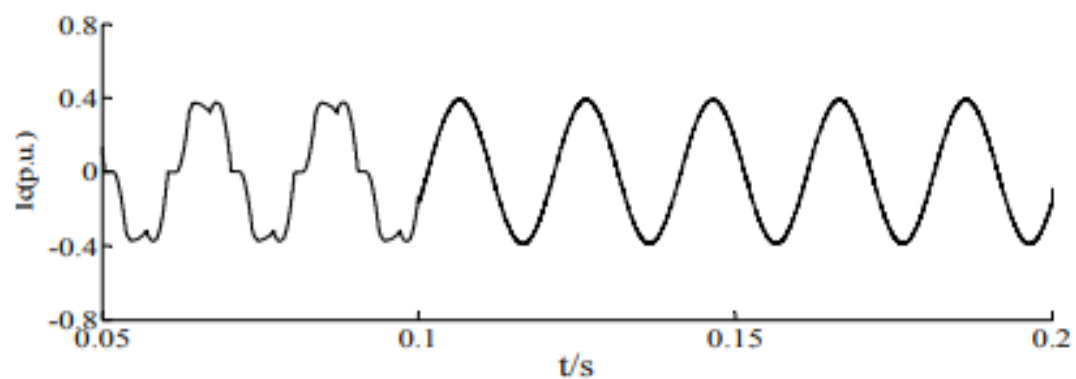

(c)

Figure 7. The simulation results for straight driven PMSG WT with an auxiliary GSC under normal conditions In Figure 7(a), the solid line corresponds to the phase-a grid voltage, and the dashed line corresponds to the phase-a output current of the main GSC, i.e., the grid-connected current of the main GSC (with a measured current direction that was opposite to the actual flow). Figure 7(a) demonstrates that GSC transfers the active power extracted from the wind turbine to the grid at a power factor of 1 . The nonlinear load in the system produced various harmonics in the grid current. At $t=0.1 \mathrm{~s}$, the auxiliary GSC initiated APF control and the harmonic compensation current is injected to the grid, as shown in Figure 7(b). It can be found from Figure 7(c) that the grid current was significantly improveddue to this compensation. Therefore, it is evident that the system successfully unified control for the wind power integration and the active power filter under normal operating conditions.

\section{Conclusion}

In this paper, a novel topology is developed for a direct-driven PMSG wind turbine system, in which an auxiliary grid-side converter is paralleled with the grid-side converter to enhance low voltage ride-through capability and improve power quality. Under normal conditions, the main GSC ensures that the wind turbine system is smoothly connected to the grid, whereas the auxiliary GSC operates in APF mode to compensate for the harmonic current and to improve the power quality of the grid. During grid faults, a hierarchical low voltage ride through strategy for generator-side converter, main GSC and auxiliary GSC is presented, which provides reactive support to the power grid and maintains the energy balance of the system to achieve a low voltage ride through requirement that complies with grid codes. The comparison of the different wind turbine generators were conducted pertaining to setup generator's fault aspects, Electrical power generated from two different generators at different wind speeds, the current harmonic distortions of PMSG generators and outcome of unbalanced load on two different generators.

\section{REFERENCES}

1. Liang Yuan (2020), "ADVANCED PMSG-BASED WIND FARM CONTROL FOR GRID INTEGRATION”. " IEEE Trans. Power Syst., vol. 32, no. 6, pp. 4708-4720 
2. MujaddidMorshed Chowdhury(2019), "Modelling and Control of Direct Drive Variable Speed Wind Turbine with Interior Permanent Magnet Synchronous Generator". IEEE Trans. Ind. Appl., vol. 38, no. 6, pp. 1622-1626, Nov./Dec. 2019

3. Elbeji, O., Hamed, M. B., \&Sbita, L. (2018). PMSG Wind Energy Conversion System: Modeling and Control. International Journal of Modern Nonlinear Theory and Application, 3(03), 88

4. D. Gautam, V. Vittal, and T. Harbour, "Impact of increased penetration of DFIG-based wind turbine generators on transient and small signal stability of power systems," IEEE Trans. on Power Systems, vol. 24, no. 3, pp. 1426-1434, Aug. 2009

5. Chen, Zhe, Josep M. Guerrero, and FredeBlaabjerg. "A review of the state of the art of power electronics for wind turbines." IEEE Transactions on power electronics 24, no. 8 (2019): 18591875.

6. Nguyen, T.H.; Lee, D.C.; Song, S.H.; Kim, E.H. Improvement of Power Quality for PMSG Wind Turbine Systems. In Proceedings of the Energy Conversion Congress and Exposition (ECCE 2010), Atlanta, GA, USA, 12-16 September 2017.

7. A. S. Bahaj, "Generating electricity from the oceans," Renewable and Sustainable Energy Reviews, vol. 15, no. 7, pp. 3399 - 3416, 2016.

8. M. Rahimi, "Modeling, control and stability analysis of grid connected PMSG based wind turbine assisted with diode rectifier and boost converter," Int. J. Electr. Power Energy Syst., vol. 93, pp. 84-96, Dec 2017.

9. M. Rahimi, "Modeling, control and stability analysis of grid connected PMSG based wind turbine assisted with diode rectifier and boost converter," Int. J. Electr. Power Energy Syst., vol. 93, pp. 84-96, Dec 2017.

10. E. Veilleux, and P. W. Lehn, "Interconnection of Direct-Drive Wind Turbines Using a SeriesConnected DC Grid," IEEE Transactions on Sustainable Energy, vol. 5, no. 1, pp. 139-147, Jan. 2016. 